Original article (short paper)

\title{
Monitoring the training intensity and recovery with a psychometrics approach: a gender comparison with young athletes
}

\author{
Ramon Cruz \\ Rafael Azevedo \\ Romulo Bertuzzi \\ Universidade de São Paulo, USP, São Paulo, SP, Brazil \\ Danilo L. Alves \\ Universidade Federal do Paraná, UFPR, Curitiba, PR, Brazil \\ Fernando R. De-Oliveira \\ Universidade Federal de Lavras, UFLA, Lavras, MG, Brazil \\ Jorge R.P. Lima \\ Universidade Federal de Juiz de Fora, UFJF, Juiz de Fora, MG, Brazil
}

\begin{abstract}
Aim - The purpose of present study was verify if the RPE-training session differs between females and males during the track and field training and if biological maturity (BM) has interference on this response. Methods: Seventyfive athletes (13-15 years old) have participated of study, with 38 male 37 female. Five training sessions of track and field were prescribe and monitoring by RPE-training session (intensity) and Total Quality Recovery (TQR) (recovery). Results: There was no statistical difference between males and females on 75-meters run, long jump and shot put. Otherwise, for training of 250 and 1000-meters females related higher RPE-values than males $3.68 \pm 0.79,3.26 \pm 0.56, p<0.01$ and 4.14 $\pm 0.94,3.72 \pm 0.89, \mathrm{p}<0.05$; respectively. Even when controlling the effect of biological maturity the same results were observed to 250-meters F1,73 $=2.060 ; \mathrm{p}=0.002$ and 1000-meters F1,73 $=0.997 ; \mathrm{p}=0.036$. There was no difference for TQR between genders. Conclusion: The comparison the RPE-training session of females and males indicated there were difference to 250 and 1000-m training sessions, females have more RPE-training sessions than males. Additionally, there were no differences between genders for recovery parameters, even controlling BM.
\end{abstract}

Keywords: biological maturity, RPE, TQR, training, adolescent.

\section{Introduction}

Coaches are constantly challenged to precisely prescribe the training intensity, specially with young athletes and sports which include several different disciplines, like track and field (running, jump and throw). A possible tool to control the training intensity is rating of perceived exertion method (RPE-method) ${ }^{1,2,3}$. However, a special attention must be taken since previous studies have demonstrated that male and female athletes perceived different intensity to the same training session ${ }^{4,5}$. For example, Kellmann, Altenburg, Lormes, Steinacker. ${ }^{4}$ demonstrated that female athletes perceived the effort in a greater magnitude than male athlete with similar training sessions. Otherwise, a study conducted by Lupo, Capranica, Cortis, Guidotti, Bianco, Tessitore ${ }^{6}$ with young Taekwondo athletes did not show statistical difference between the genders to RPE-training. Thus, this topic is not well established and it is interest to note these studies, except Lupo, Capranica, Cortis, Guidotti, Bianco, Tessitore ${ }^{6}$ do not considered youth population.

In this sense, it is expected that the biological maturity (BM) to be considered because of all physical and psychologic changes that occurred on these period ${ }^{7,8,9}$. Furthermore, it is widely established that females reach the mature state before the males with the same age, thus it is indispensable to consider the BM for comparisons between genders with the range of age (13 - 15 years old). Additionally, it is necessary an experimental design with high ecological validity, a large number of athletes to make the analysis and training session well controlled. Besides that, in regardless young track and field training is necessary to considerer all disciplines that compose the modality (running, jump and throw).

In summary, previous studies have demonstrated different results about training intensity (based on RPE-method) between genders to the same training session. Additionally, has been demonstrated that the stress of training is more pronounced in female athletes ${ }^{4,5}$. Considering the knowledge available about how the intensity of exertion is perceived by male and female athletes, it is possible to consider that the intensity of training based on RPE-training session method could be altered too. Furthermore, it is necessary to control the BM because all changes that occurred in this period. In this sense, the aim was verify if the RPE-training session differs between females and 
males during the track and field training and if BM has interference on this response.

\section{Methods}

\section{Participants}

Seventy-five young athletes, of the same category (under-16, 13 - 15 years old), of both genders (38 males and 37 females) participated in the present study. They belonged of the same category (under-16), aged between $13-15$ years old. All athletes have at least six months of training and were participating on official track and field competitions. All participants and their respective responders received verbal explanation about of this research and written informed consent before participation in the study. The local ethical committee of Federal University of Juiz de I approved all procedures (protocol number: 945.274).

\section{Experimental design}

The experimental sessions were performed during seven consecutive days. In the first day, the subjects did anthropometric measures and anamnesis. The disciplines that were considered on training sessions were running $(75,250$ and 1000-m running), jump (long jump) and throw (shot put). During the experimental period, they were instructed to keep their same pattern of feed. Previously to the training sessions it was used the Total Quality Recovery (TQR) to evaluate the global recovery ${ }^{10}$ and 30 minutes after each training session, the athletes was asked the rate of perceived exertion (CR-10) ${ }^{2,3}$. The figure 1 shows an overview of the experimental design.

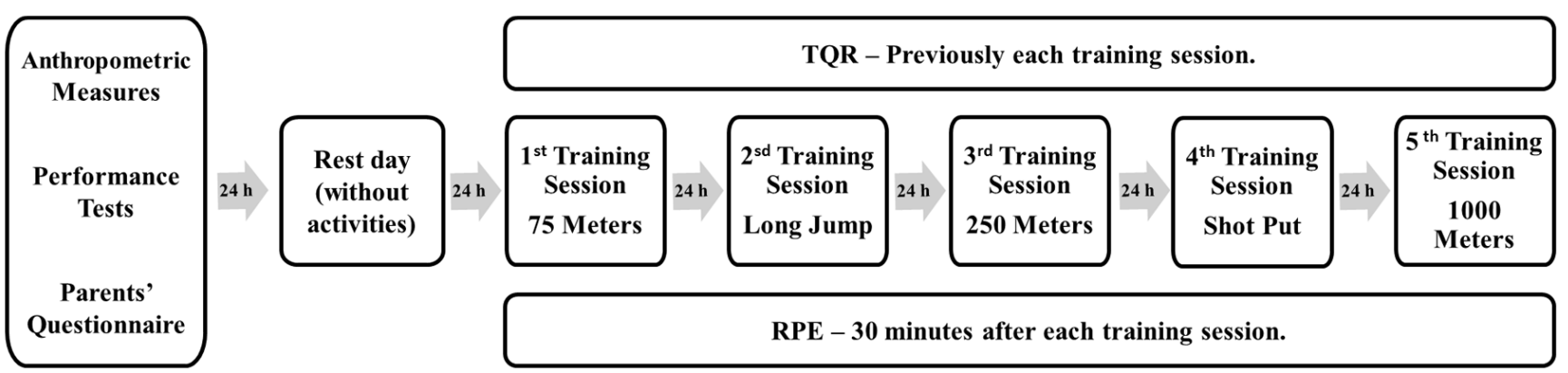

Figure 1. Experimental design.

\section{Methodology}

\section{Anthropometry Measurements and Biological Maturity}

Anthropometry measurements were performed according to the procedures described by Isak ${ }^{11}$. Participants were weighed to the nearest $0.1 \mathrm{~kg}$ using an electronic scale (Filizola, model ID 1500, São Paulo, Brazil). Height was measured to the nearest 0.1 cm using a portable stadiometer (Welmy, model W200/5, Santa Bárbara d'Oeste, Brazil). Skinfold thickness was measured to the nearest $0.1 \mathrm{~mm}$ at four body sites (i.e. subscapularis, supra iliac, triceps and leg) using an adipometer (Sanny, Model Classic Scientific, São Bernardo do Campo - Brazil). The median of three values of skinfolds it was used.

The method of The Predicted Mature Stature (PMS) was used to estimate the BM. This method was propose by Khamis and Roche ${ }^{12,13}$ and is a non-invasive method, based on decimal age, athletes anthropometry measurements (weight and stature) and their parents measurements. The percentage of PMS (PPMS) is obtained by the following equation:

PPMS $=100 *($ Current Height/PMS $)($ Eq. 1)

\section{Training Sessions}

To improve the control of training session's intensity, five days of training to all athletes were prescribed according to under-16 category. Previously of experimental procedures, all coaches were consulted and ensured that their athletes were familiarized with structure and all activities proposed. It is import to highlight that all training sessions have the same structure and duration. A typical training session was composed by 120 minutes, divided by warm-up (10 min) and stretching ( $5 \mathrm{~min})$, main part (90 min) and active recovery (jogging and lightly stretching - $15 \mathrm{~min}$ ) and all athletes completed the five training sessions. The activities of main part were based on his respective discipline. Thereby, the table 1 shows the characteristics of main part.

\section{Monitoring the Intensity of Training Session}

To estimate the intensity of training session the RPE-method was used, based on Category Ratio Scale CR-10. After 30 minutes from training session ending, the athletes were asked "How was your workout?" 2,3 . To estimate the recovery between 
training sessions it was used the scale proposed by Kentaa and Hassmén ${ }^{10}$. The "total quality recovery" (TQR) has been used as a noninvasive and practical tool to monitor athlete's recovery during the weeks of training ${ }^{14}$.

Table 1. Training Sessions Description.

\begin{tabular}{|c|c|c|c|c|c|}
\hline Duration & $75 \mathrm{~m}$ & Long Jump & $250 \mathrm{~m}$ & Shot Put & $1000 \mathrm{~m}$ \\
\hline 15 & Warm-Up & & & & \\
\hline 90 & $\begin{array}{l}\text { Technical of } \\
\text { High Speed } \\
\text { Running } \\
\text { Short Sprints } \\
\text { Running. }\end{array}$ & $\begin{array}{l}\text { Drills for } \\
\text { jumps, } \\
\text { Series of } \\
\text { jumps. }\end{array}$ & $\begin{array}{l}\text { Technical of } \\
\text { Speed Run- } \\
\text { ning, } \\
\text { Long Sprints } \\
\text { Running. }\end{array}$ & $\begin{array}{l}\text { Drills for shot put, } \\
\text { Exercises to Shot Put } \\
\text { Technique, } \\
\text { Throw Resistance } \\
\text { training. }\end{array}$ & $\begin{array}{c}\text { Technical of long } \\
\text { distance running, } \\
\text { Continuous run- } \\
\text { ning, Fartlek. }\end{array}$ \\
\hline 15 & & & Active Rec & & \\
\hline
\end{tabular}

\section{Statistical Analysis}

The results of the descriptive statistics were reported as mean and standard deviations $( \pm \mathrm{SD})$. Parametric assumptions were assessed by the Shapiro-Wilk test and the Levene test. To compare the RPE-training session between males and females it was used Mann-Whitney test. The analysis of covariance was used to test the RPE-training session between genders, but controlling the biological maturity (covariate). The effect size of variables with significance difference the effect size was estimate. Statistical significance was set at $\mathrm{p}<0.05$.

\section{Results}

The table 2 presents descriptive characteristics of all athletes and TQR values. As expected females were more advanced biological maturity $(\mathrm{PPMS})(\mathrm{p}<0.01)$. Other variables associate with BM also had significance difference (weight, height and sum of SF). Regarding the recovery, during the all training session females and males reported "Good Recovery", which refers of 15 score.

The figure 2 shows the mean of training intensity of each training session females males for both genders. The RPE-training values for resistance of speed and endurance training sessions had statistical difference $(p=0.006$ and $p=0.044$, respectively), where females values were higher than males. Even when controlling the biological maturity the RPE-training sessions of 250 and 1000 meters were significantly different between females males genders $\left(\mathrm{F}_{1,73}=2.060 ; \mathrm{p}=0.002\right.$ and $\mathrm{F}_{1,73}=0.997 ; \mathrm{p}=$ 0.036 , respectively). The effect size analysis demonstrated that moderate (0.62) and small (0.46) magnitude to 250-m and 1000$\mathrm{m}$ training session, respectively. It is important to highlight that the training load is obtained by multiplying the duration of the exercise bout by RPE-training session; however, to enhance the control of experimental protocol, all training sessions were standardized (120 minutes duration).

Table 2. Descriptive and Total Quality Recovery values of participants.

\begin{tabular}{lccc}
\hline & Females & Males & p value \\
\cline { 2 - 4 } & Mean \pm SD & Mean \pm SD & 0.29 \\
\hline Age (years) & $14.55 \pm 0.82$ & $14.30 \pm 0.85$ & 0.04 \\
Weight (kg) & $53.25 \pm 8.09$ & $58.31 \pm 14.04$ & $<0.01$ \\
Height (cm) & $162.20 \pm 7.35$ & $169.08 \pm 9.29$ & $<0.01$ \\
Sum of SF (mm) & $44.29 \pm 12.88$ & $31.59 \pm 15.65$ & $<0.01$ \\
PPMS (\%) & $98.00 \pm 1.49$ & $94.26 \pm 4.19$ & 0.50 \\
\hline TQR & & & 0.99 \\
\hline 75 m (s) & $15.84 \pm 1.61$ & $15.97 \pm 1.52$ & 0.14 \\
Long Jump (m) & $15.81 \pm 1.56$ & $15.89 \pm 1.83$ & 0.77 \\
250 m (s) & $15.30 \pm 1.61$ & $15.87 \pm 1.89$ & 0.91 \\
Shot Put (m) & $15.57 \pm 1.71$ & $15.82 \pm 1.80$ & $15.61 \pm 1.82$ \\
1000 m (s) & $15.46 \pm 1.61$ & & \\
\hline
\end{tabular}




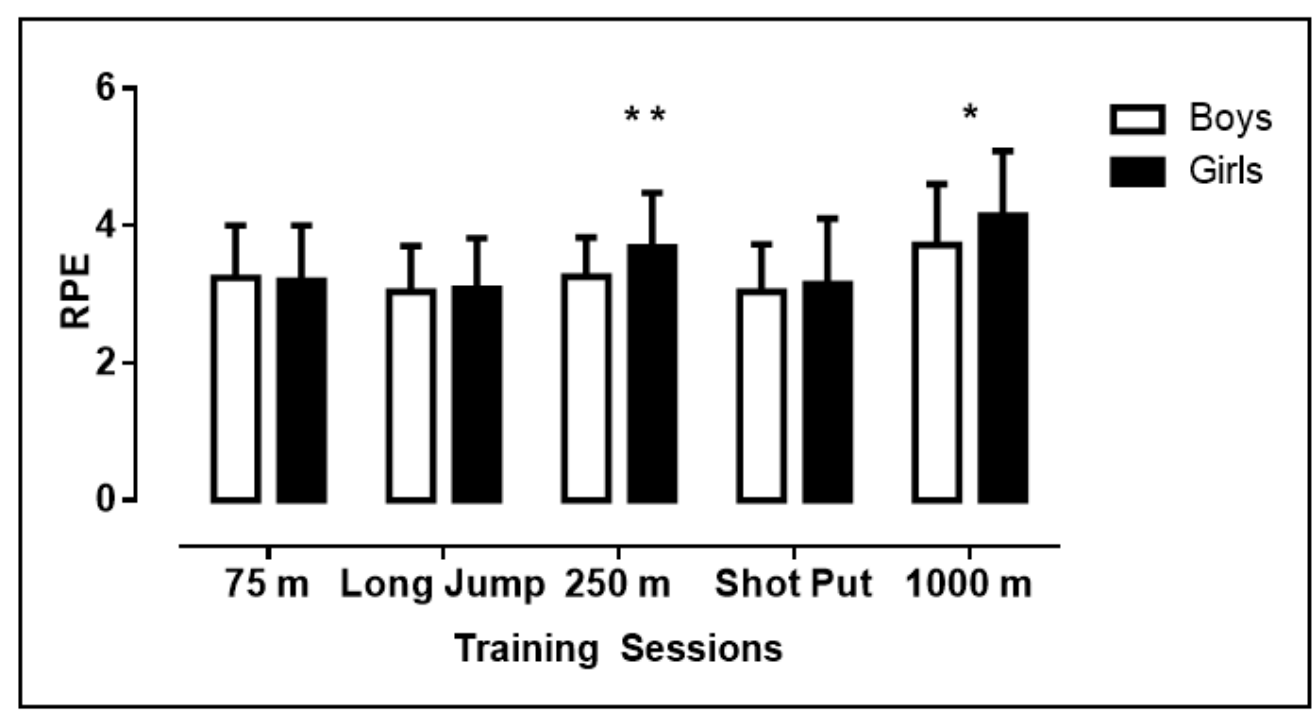

Figure 2. RPE-training sessions. ${ }^{*} \mathrm{p}<0.05 ; * * \mathrm{p}<0.01$.

\section{Discussion}

Control the training intensity is essential to enhance performance. In the present study, the comparison of RPE-training session between females and males indicated no difference on training 75-m, long jump and shot put. Otherwise, there were statistical difference for 250 and $1000-\mathrm{m}$ training sessions, where females had higher RPE-training sessions values than males. Moreover, this difference persisted even when biological maturity effect was controlled. Additionally, there was no difference for recovery parameter by TQR. To the best of our knowledge, this is the first study to consider specific training sessions of track and field and compare the RPE-training sessions of male and female athletes. Furthermore, it were considered the biological maturity on the analysis, controlling and prescribed the same training session for a large number of athletes (duration and exercise).

There are several studies demonstrating how the rating of perceived exertion can be used to control the intensity of exercise and training session ${ }^{1,2,3,6,15}$. However, distinct results have been reported when the comparison between the genders are taken into account ${ }^{5,6}$. For example, di Fronso, Nakamura, Bortoli, Robazza, Bertollo ${ }^{5}$ have indicated that female athletes have different perceived different of psychophysical stressors. On other hand, Lupo, Capranica, Cortis, Guidotti, Bianco, Tessitore ${ }^{6}$ have not indicated difference on RPE training session between genders during taekwondo training sessions. Our results demonstrated that training sessions of speed, jump and throw were not different between females and males, even controlling the BM. In accordance with our results of skin fold, we can to speculate that difference in RPE-training sessions of 250-m and 1000-m running was pronounced because the female athletes has more total body mass, which are not necessary muscle involved in mechanical work, this condition could cause more physical stress and therefore, higher values of RPE-training session.

The main difference for RPE-training sessions were the 250-meters and 1000 meters training sessions, which females had higher values than males, as demonstrated by Kellmann, Altenburg, Lormes, Steinacker ${ }^{4}$. Additionally, have been speculated that physiological signal is more pronounced in running exercises and then caused greater values of RPE-training session $^{16}$. di Fronso, Nakamura, Bortoli, Robazza, Bertollo have demonstrated that even with similar training session, female athletes perceive different the training stimulus and stress responses. Considering the higher values for female athletes, the recovery could be affected and the RPE-training session values. During the week of training, the parameters of recovery did not differ between male and female athletes, thus we believe that the intensity of training sessions and time between each session allowed all athletes to have a good recovery. Furthermore, we speculated that only during high intense consecutive training sessions could do different in recovery measure by TQR. Kellmann, Altenburg, Lormes, Steinacker ${ }^{4}$ demonstrated that female athletes indicated low recovery values in different parameters (sleep, feeding, age, and emotional factors/behavior/cognitive/social).

Despite the advances brought by our results, some limitations and suggestions for future studies could be considered, such as, more training sessions of each disciple as well as greater and lower intensities. As demonstrated by Impellizzeri, Rampinini, Marcora $^{15}$ and Viru ${ }^{17}$, the intensity variability could cause pronounced stress and it is important to understand how females and males feel the training stimulus. The practical analysis of magnitude-based inference shown moderate and small effect size to $250-\mathrm{m}$ and $1000-\mathrm{m}$ training sessions, respectively. Even though, we suggest that RPE-training session could be used during track and field training, specially during the training sessions of resistance of speed and endurance.

\section{Conclusions}

In summary, the comparison the RPE-training session of females and males indicated there were no difference to training of $75-\mathrm{m}$, 
long jump and shot put. Otherwise, to 250 and 1000-m training sessions, females have more RPE-training sessions than males. Additionally, there were no differences between genders for recovery parameters, even controlling BM. Thus, RPE-training session and TQR can be used to controlling training intensity and recovery, respectively. However, more attention it is necessary to $250-\mathrm{m}$ and $1000-\mathrm{m}$.

\section{References}

1. Borresen J, Lambert MI. The quantification of training load, the training response and the effect on performance. Sport Med. 2009;39(9):779-95.

2. Foster C, Daines E, Hector L, Snyder AC, Welsh R. Athletic performance in relation to training load. Wis Med J. 1996;95(6):370-4.

3. Foster C, Heimann KM, Esten PL, Brice G, Porcari JP. Differences in perceptions of training by coaches and athletes. South African J Sport Med. 2001;8(2):3-7.

4. Kellmann M, Altenburg D, Lormes W, Steinacker JM. Assessing stress and recovery during preparation for the world championships in rowing. Sport Psychol. 2001;15(2):151-67.

5. di Fronso S, Nakamura FY, Bortoli L, Robazza C, Bertollo M. Stress and recovery balance in amateur basketball players: Differences by gender and preparation phase. Int J Sports Physiol Perform. 2013;8(6):618-22.

6. Lupo C, Capranica L, Cortis C, Guidotti F, Bianco A, Tessitore A. Session-RPE for quantifying load of different youth taekwondo training sessions. J Sports Med Phys Fitness. 2016; 57(3):189-94.

7. Figueiredo AJ, Coelho e Silva MJ, Malina RM. Predictors of functional capacity and skill in youth soccer players. Scand J Med Sci Sports. 2011;21(3):446-54.

8. Malina RM, Bouchard C, Bar-Or O. Growth, Maturation, and Physical Activity. Champaign, Ill.: Human Kinetics Books; 2004.

9. Silva DRP, Fernandes RA, Ohara D, et al. Correlates of sports practice, occupational and leisure-time physical activity in Brazilian adolescents. Am J Hum Biol. 2016;28(1):112-7.

10. Kenttä G, Hassmén P. Overtraining and recovery. Sport Med. 1998;26(1):1-16.

11. MacDougall JD, Wenger HA, Green HJ. Physiological Testing of the High-Performance Athlete. Champaign, Ill.: Human Kinetics Books; 1991.

12. Khamis HJ, Roche AF. Growth outcome of" normal" short children who are retarded in skeletal maturation. J Pediatr Endocrinol Metab. 1995;8(2):85-96.

13. Khamis HJ, Roche AF. Predicting adult stature without using skeletal age: the Khamis-Roche method. Pediatrics. 1994;94(4):504-7.

14. Suzuki S, Sato T, Maeda A, Takahashi Y. Program design based on a mathematical model using rating of perceived exertion for an elite japanese sprinter: acase study. J Strength Cond Res. 2006;20(1):36-42.

15. Impellizzeri FM, Rampinini E, Marcora SM. Physiological assessment of aerobic training in soccer. J Sports Sci. 2005;23(6):583-92.

16. Green JM, Crews TR, Bosak a M, Peveler WW. Overall and differentiated ratings of perceived exertion at the respiratory compensation threshold: effects of gender and mode. Eur J Appl Physiol. 2003;89(5):445-50.
17. Viru A. Specific nature of training on skeletal muscle fibres: adaptations in sports training. 1995.

\section{Acknowledgments}

The authors thank CAPES for scholarship and all teams and athletes of track and field for their participation.

\section{Corresponding author}

Ramon Cruz.

Address: Departamento de Esporte . Escola de Educação Física e Esporte da Universidade de São Paulo. Av. Prof. Melo de Morais, 65, Cidade Universitária, São Paulo, SP, CEP: 05371-140, Brazil.

Email: ramoncruz@usp.br

Manuscript received on May 3, 2017

Manuscript accepted on July 21, 2017

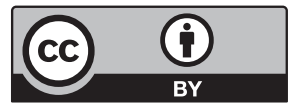

Motriz. The Journal of Physical Education. UNESP. Rio Claro, SP, Brazil - eISSN: 1980-6574 - under a license Creative Commons - Version 3.0 